\title{
Nuclear media discourses after the closure of the Ignalina Nuclear Power Plant: Is the game over?
}

\author{
प⿴囗十口 पा \\ Natalija Mažeikienè \\ ORCID: 0000-0001-8029-4907 \\ VYTAUTAS MAGNUS UNIVERSITY, LITHUANIA \\ Judita Kasperiünienè \\ ORCID: 0000-0001-6851-7637 \\ VYTAUTAS MAGNUS UNIVERSITY, LITHUANIA \\ Ilona Tandzegolskienè \\ ORCID: 0000-0002-7734-5475 \\ VYTAUTAS MAGNUS UNIVERSITY, LITHUANIA
}

DOI: 10.19195/1899-5101.12.3(24).4

\begin{abstract}
The article presents a critical discourse analysis of media coverage of the most important Lithuanian strategic object - the Ignalina Nuclear Power Plant (INPP) - in the three biggest news portals. Media news focuses mostly on certain aspects of decommissioning of the INPP - management issues and the transparency of financing mechanisms. Environmental and social aspects of the decommissioning are not sufficiently disclosed and discussed. The community of Visaginas (the satellite town for the workers of the INPP) remains an invisible and silent actor of the discourse. In the media news portals, the town is portrayed as disconnected from the INPP. This divide could be explained by assuming that after the closure of the INPP as a major feeding enterprise the town must search for a re-definition of its identity and construct this identity without nuclear energy and without the INPP. On the other hand, such a divide reflects a common trend characteristic of the entire nuclear discourse - to disempower communities and the public, create a boundary between the industry and the public, between the experts and ordinary citizens.
\end{abstract}

KEYWORDS: critical discourse analysis, Ignalina Nuclear Power Plant, media framing, media news portals, nuclear discourse, nuclear media discourse, text mining, Visaginas. 
Natalija Mažeikienė, Judita Kasperiūnienè, Ilona Tandzegolskienẻ

\section{INTRODUCTION}

The article focuses on an analysis of nuclear discourse by exploring media coverage of the Ignalina Nuclear Power Plant (INPP). Visaginas is a relatively young urban settlement, founded as a satellite town of the INPP. In the mid-1970s Russian-speaking specialists arrived from various places in the Soviet Union to build the town and the INPP. The INPP and the Visaginas town, since their foundation in 1976, are a unique region and an object of strategic importance in many aspects: security, political, economic, social, and cultural.

Due to the plant's similarities to the Chernobyl Nuclear Power Plant in reactor design and lack of a robust containment building, Lithuania, while accessing the European Union, agreed to close the INPP. The decommissioning processes of the INPP (the first block was suspended in 2004, the second in 2009; all decommissioning activities must be completed by 2038) dictate the need to create a new identity of the INPP region and promote new areas of economic activity, and new types of interaction with various stakeholders in the country. The INPP closure, decommissioning and dismantling processes have triggered major changes in the region: it is important to ensure further development of the town, which has always defined itself as a nuclear power town and as an INPP satellite.

In the article, the following research question is addressed: What nuclear discourses have been constructed on internet news portals 10 years after the closing and decommissioning of the INPP?

\section{NUCLEAR MEDIA DISCOURSES: FROM A MODERNIST NARRATIVE OF TECHNICAL PROGRESS TO THE CONSTRUCTION OF DOCILE CITIZENSHIP}

The nuclear discourse is defined as a dense network of representations and meanings of the use of nuclear power and as the formation of power and knowledge linking institutions and practices (Kinsella, 2005). The research on nuclear discourse has been conducted in many countries and it reveals a set of distinct features and peculiarities.

The nuclear discourse deals with central meanings, themes and metaphors which are associated with nuclear power and the use of nuclear energy. It is important to note that nuclear discourse covers a wide field of representations, images and ideas. For instance, anti-nuclear discourse is expressed in the nuclear imagery of literature and cinematography, e.g. the movie On the Beach (1959, dir. Stanley Kramer), Andrei Tarkovsky's Stalker (1979), HBO TV series Chernobyl (2019) and Svetlana Alexievich's Chernobyl Prayer (1997). The nuclear discourse may be found in scientific publications and conference discussions of atomic scientists and other scholars, in political debates in the process of decision making on the use of nuclear power, in the school curriculum (textbooks) and in public educational and tourist spaces (tourist sites, museums), and so on. 
The specific form of the nuclear discourse is a media discourse on nuclear power (Gamson \& Modigliani, 1989; Entman \& Rojecki, 1993; Mercado-Saez et al., 2019) which plays an important role in framing issues and constructing reality. The media discourse is "a site on which various social groups, institutions, and ideologies struggle over the definition and construction of social reality" (Gurevitch \& Levy, 1985, p. 19, cited by Gamson \& Modigliani, 1989).

Researchers recognize historically prevailing representations of nuclear power. Kinsella (2005) performed longitudinal and ethnographic studies of the nuclear discourse over 100 years in the US and distinguished repeating communicative patterns. He refers to four major themes of the nuclear discourse: mystery, entelechy, potency, and secrecy. Besides this thematic framework, by referring to the Foucauldian approach, Kinsella (2005) emphasized an interrelation between power, knowledge and construction of docile citizenship. Discursive control and regulation determine groups and agents who can speak about nuclear matters, and it defines the content of the discourse. Kinsella (2005) describes how the four themes create boundaries between experts and the public, becoming a symbolic source of hierarchic relations. The theme of mystery encompasses the tendency of presenting atoms as mysterious and godlike entities. Accordingly, humans who work with atoms (nuclear scientists) gain the status of gods or at least can be considered as nuclear priests. Secrecy has been an integral part of nuclear development when nuclear research on the atomic bomb was conducted and later it was part of the military industry during nuclear proliferation in the context of the Cold War. During the 1950s, the theme of the potency and power of nuclear energy was emphasized by promoting the image of the powerful nuclear genie. This image of potency goes in line with the "modernist discourse" of the Enlightenment, stressing inevitable and linear progress and an approach of subjugating the natural world.

Kinsella (2005) highlighted that mystery, secrecy and potency established a boundary between the representatives of the nuclear industry (experts, scientists) and the public, created the divide between the "technical" and "public" spheres, and disempowered public participation in the nuclear domain. Kinsella points out that mystery, secrecy, entelechy, mastery over the powerful atom are portrayed in the nuclear discourse as intellectually difficult and out of the intellectual reach of ordinary people. All these features of the discourse exclude the public from the decisionmaking process and constrain its agency.

Gamson and Modigliani (1989), in describing the patterns of media discourse on nuclear power, stress the dualism of representations of nuclear energy when the use of nuclear energy was presented in the form of an "either/or" structure. At the same time, the media discourse on nuclear energy starting from the nuclear bomb blasts in Hiroshima and Nagasaki in 1945 was focusing on depicting the destructive power of the atom. In the late 1950s and early 1960s, the movement against the atmospheric testing of nuclear weapons in the US brought to public attention the long-range dangers of radiation. 
In the 1960s the media discourse presented nuclear power as technological progress. Anshelm (2010) who focused on Swedish nuclear energy discourse in the 1950s and carried out an analysis of the texts produced over more than a decade, identified similar meanings, themes, and patterns on an optimistic and promising picture of the Atomic Age when nuclear energy was portrayed as a symbol of a new future with science-fiction-like visions of the revolutionary qualities of the new technology. The scholar pointed out that this narrative produced an overwhelming rhetoric of the progress integrated with a technological determinism.

Formulations that characterized scientific and technological work as "witchcraft," "atomic enchantment" or the nuclear reactor as a "witch oven" were not unusual, and atomic physics was commonly comprehended as risen from "mystical depths." (Anshelm, 2010, p. 48)

In this pattern of envisioning the use of nuclear energy as magic and mystery, nuclear scientists and engineers are depicted as magicians and wizards who can accomplish miracles. A very broad range of metaphors and myths is used in this narrative of the re-enchantment of the world. The use of nuclear technology is described by referring to metaphors, myths and images of the demon, "the opening of Pandora's box," the genie in the bottle, and Aladdin's lamp, a savior from evil whereas a man (nuclear scientist) like a god struggles with nature, "puts rein and harness on atomic power," becomes "the master of matter." According to Anshelm, the deployment of powerful myths in combination with a rationalistic, scientific, economic, political and moral argumentation allowed the carrying out of a successful popularization of the benefits of nuclear energy and created substantial symbolic, political, and civic support to the national project of the development of the nuclear industry.

Authors working on the nuclear discourse continue the analysis of key themes distinguished and described by Kinsella (2005) and Catellani (2012) while analyzing texts of pro-nuclear storytelling (advertisements, videos, websites, "nuclear forums") in France, Italy and Belgium, unveil discursive strategies which encompass a tendency to the "disempowerment" of the public and narrow down spaces for public discussion. The second tendency revealed in the study performed by Catellani (2012) is the construction of a "modernistic" basic narrative of nuclear power as an inevitable technological development and nuclear power as a subject out of the control and intervention of normal citizens, excluding real participation in decisions about its development. In the study, Catellani (2012) delineates how a pro-nuclear discourse is constructed, when nuclear power is associated with technical progress and presented as a source of evolution toward the development of humanity. The author also distinguishes the discourse participants and reveals which organizations stand behind this discourse. It is the organizations that are either nuclear energy corporations or producer associations that have the economic power to pay for advertising and communications and have political power (namely, the French, British and Belgian organizations Areva, Electrabel, Westinghouse and Tractebel). 


\section{CONSTRUCTING A NUCLEAR POWER CULTURE IN MEDIA DISCOURSE}

Gamson and Modigliani (1989) in analyzing media discourses on nuclear power discuss construction of a nuclear culture in the media discourse. The authors distinguish "media packages" as interpretative frames which construct a meaning on an issue (in this case on nuclear power) over time and create an issue culture (in this case - the culture of nuclear power). The interpretative media package usually has a central organizing idea, a frame, which makes sense of relevant events. New emerging events are incorporated into these interpretive frames. "This frame typically implies a range of positions, rather than any single one, allowing for a degree of controversy among those who share a common frame" (Gamson \& Modigliani, 1989, p.3). While creating the issue culture the media package refers to the cultural heritage and resonates with larger cultural themes, narrations, stories and myths. Examples of these cultural themes deriving from the cultural heritage in creating the culture of nuclear power could be the above-mentioned metaphors and myths described by Kinsella (2005) and Anshelm (2010) when the use of nuclear technology is depicted by referring to images of the demon, "the opening of Pandora's box," the genie in the bottle, and Aladdin's lamp, "witchcraft," etc. Gamson and Modigliani (1989) mention the link of the media package of progress with a larger cultural theme of technological progress which is rooted in cultural values of efficiency, technological innovation, economic expansion and in images of inventors as cultural heroes (it could be compared with images of nuclear scientists as nuclear priests [Kinsella, 2005]), magicians and wizards (Anshelm, 2010). The cultural themes are created together with counter-themes which are parts of the same frame. As an example of cultural image from a counter-theme in the nuclear discourse could be mentioned a story about Frankenstein's monster who revolted against its creator and many other cultural depictions of "mad and crazy science."

Besides the media package as the frame of interpretation, Gamson and Modigliani (1989) point out the role of sponsors of the media discourse and media practices. The media packages allow sponsors to frame the nuclear issue in a certain way and mobilize audiences for collective action. Public officials and politicians and nuclear industry companies are the main sponsors of the pro-nuclear media discourse. Anti-nuclear media discourse is promoted by social movement organizations and environmental groups. The third important element distinguished by scholars is media norms and practices, where journalists and media companies play a prominent role, since they become an important medium between sponsors of discourses and audiences. Media discourse becomes a way to form a certain public opinion of the audiences and mobilize for a certain political action.

At the same time, according to Gamson and Modigliani (1989), interrelation between media discourse and public opinion should be understood in a more dialectic way by avoiding a causal explanation when the discourse is seen as a cause of public opinion. Scholars point out that the media discourse is just a part of meaning 
construction and the interrelation between discourse and public opinion is more complex. Entman and Rojecki (1993) while analyzing media coverage of the U.S. anti-nuclear movement of the early 1980s revealed the role of journalists and sponsors of media framing. Unfavorable media coverage of the freeze movement and journalists' framing judgments which were influenced by elite sources weakened the anti-nuclear movement's recruitment efforts and ability to build consensus and mobilize participation. At the same time, "media practice seems to provide elites a much broader range of legitimate communicative options, with less danger of being downgraded for partisanship, emotionality, or insufficient expertise" (Entman \& Rojecki, 1993, p. 168).

The analysis of news texts in Spain in 2008-2012 (Mercado-Saez et al., 2019) uncovered similar tendencies when the "sponsors" of the media discourse and stakeholders representing political and economic interests dominated the media discourse. Sources of competing discourses, i.e., political parties in Spain, regional governments which have different views on nuclear power, are major participants of the nuclear debates. A discussion on the use of nuclear sites is one of the significant themes of the nuclear debates in the media discourse. In Spain, the closure of the oldest nuclear power plant in Garona has become an important theme of the media debate. Two competing discourses are generated by influential political stakeholders (different regional governments) which either support the reopening of the Garona plant by referring to the economic rationale (new jobs) or, on the contrary, insist on the closure of the plant by referring to safety risks. Other influential stakeholders representing the Spanish nuclear industry promote an argument of economic growth and environmental cleanliness of nuclear energy in comparison with fossil fuels. Opinions of other stakeholders (i.e., environmentalists) which raise environmental concerns are presented very scarily in the Spanish press. As the authors (Mercado-Saez et al., 2019) notice, the media do not fulfill their function to inform the public and enable them to engage into a reflected debate. In this way, the ideal of deliberative democracy, stating that important social issues need to be discussed by different groups, is not realized. Some potential discursive participants are not involved in the debate. At the same time, mass media are a very important agent of the discourse. Media coverage provides little space for other actors, such as scientists and experts, environmental associations or citizens.

Similar pro-nuclear discourse tendencies are recognized in Turkey, where the use of nuclear energy is associated with technological progress, increased productivity and competitiveness, economic growth, an environmentally friendly, secure energy supply and stability of energy prices (Balkan-Sahin, 2019). Nuclear energy is presented as superior to power plants that use imported energy sources, such as coal and natural gas-operated plants, and it is viewed as cleaner than fossil fuels. The critical discourse analysis and the neo-Gramscian approach reveal what agents produce hegemonic nuclear discourses. The government has legitimized its policy choice on nuclear power plants through the discourse. Economic and political 
interest groups (business and industrialists' associations) are other prominent and powerful participants of the public discourse.

The revealed themes of nuclear energy: mystery, secrecy, potency and technological determinism (entelechy), in the nuclear discourse (Kinsella, 2005; Anshelm, 2010) and related divide between experts and the public encourage the search for communicative strategies which could help certain stakeholders reduce the gap between the nuclear experts and ordinary citizens. Scholars analyzing nuclear discourses describe how pro-nuclear PR campaigns are arranged by nuclear industry stakeholders and how pronuclear storytelling and narratives are constructed. Hanninen and Yli-Kauhaluoma (2014) describe how the constructor of the Onkalo spent nuclear fuel storage (Eurajoki, Finland) portrays it to the local community in order to influence the understanding of the disposal risk, build trust and gain public approval for the construction project. The authors carried out a framing analysis of the newsletters published on the company's website in the years 2000-2014, trying to delineate how the nuclear waste storage issue has been framed. The PR campaign run by the Posiva company is aimed at the construction of an imagined nuclear community around the storage and seeking to shape the understanding of risks and create trust in nuclear experts. Some specific communicative and discursive strategies are deployed in this PR campaign when, for instance, trust is created by carefully choosing words for final disposal and diminishing perceived risks, by depicting the Onkalo project as our project as a project of the whole community and by creating an imagery of togetherness. In the narrative analysis of this campaign, the authors (Yli-Kauhaluoma \& Hanninen, 2014) recognize the storylines of the pro-nuclear storytelling. Five themes emphasize the "continuum of the good": retrieving of the cultural heritage of the region, the economic advantages and wellbeing associated with the construction of the Onkalo storage (new businesses and jobs, better public services), adapting the construction project to the local natural environment. Nuclear managers and experts are portrayed as family members and part of the local community. This analysis shows that some previous communicative strategies and imagery which were used in the first stages and decades of nuclear discourses are replaced by more sophisticated narrative strategies which seek to diminish the boundaries between the industry and the public, between the experts and ordinary citizens. However, the interest of implementation of the industrial nuclear project is the main rationale and aim behind these narratives. This form of communication differs from debates which could be arranged in the media and where different stakeholders could express their contesting opinions and views.

\section{NUCLEAR ENERGY AS PART OF THE ENERGY SECURITY DISCOURSE: A HISTORICAL OVERVIEW}

In Lithuania, the public discourse of energy security has been developed for over two decades and representatives of politics, science and the mass media are the most active participants in it. The International Energy Agency and other organizations 
characterize energy security as an indicator of a state's welfare, when the concept of energy security is linked to a ceaseless supply of energy, autonomy, competitive prices and purposefulness leading toward welfare of the society (Leonavičius \& Genys, 2017). From the earliest days of Lithuania's regained independence, energy security has been related to independence of the national energy system as well as economic and political independence from supplies from Russia.

In scientific literature, the use of nuclear energy is evaluated and characterized in various ways: on the one hand, it is an advantage because it is "cheap" energy and the "air is cleaner without carbon dioxide"; on the other hand, it is a disadvantage and the issue of safety is pointed out. As Evans and Steven (2007) have it, in the social sciences energy security is dealt with by emphasizing the threats to the environment which occur due to the development of science and technologies, predicted risks, uncertainty and unpredictability. Moreover, in Lithuania, alongside energy independence and economic benefit, the issue of technological and environmental safety is discussed; it is discussed in stronger relation to the life cycle of the INPP and the closure of the reactors, while also emphasizing the threat of nuclear catastrophe referring to the poignant experience and catastrophe that Fukushima underwent in 2011, or while observing the currently proceeding construction of the Astravets Nuclear Power Plant in Belarus and analyzing the scenarios of its operation.

By employing the public discourse, a purposeful understanding by society about energy security, the risks of nuclear energy, its benefits, threats and opportunities are being formed. Moreover, an uneven distribution of themes is observed; the political and economic aspects are listed as the dominating themes, whereas environmental and social issues are lacking attention.

When carrying out quantitative analysis of the media discourse in 2013, Leonavičius and Genys (2017) revealed the expressions and words which were most frequently used in mass media as characterizing the most relevant themes: energy security is called "the sacred goal," a matter of paramount importance, independence, and the dependence on energy experienced by Lithuania is called "the loop," or the "Russian yoke." Media discourses attempt to comprehensively describe and discuss all the situations and consequences which are related to the closure of the INPP and allocated funding for termination of exploitation of the INPP. Moreover, in this period (ca. 2012) there were discussions on the construction of a new nuclear power plant and negotiations with a strategic investor, the Japanese corporation Hitachi. In case of an agreement with the strategic partner and having received the consent of Lithuanian citizens regarding the construction of a new power plant near the town of Visaginas, the new power plant would have started producing electrical energy in 2018-2020. The situation was strongly discussed in the mass media, naming two possible major sources: nuclear energy and construction of a liquefied natural gas terminal.

Over the analyzed period of 2008-2012, politicians dominate in the media discourse. Moreover, major themes become apparent: a geopolitical threat (likely energy dependence on Russia) and nuclear energy as a long-term strategic project. 
The currently valid National Energy Strategy issued in 2012 is called the Strategy of Energy Independence (Augutis et al., 2016). The analysis conducted by Baločkaitè and Rinkevičius (2009) consolidates the information presented earlier in terms of active participation of politicians in the media discourse and have it that over the period of investigation of the media coverage (April-July 2008) 60\% of published articles were constructed on the grounds of statements of political activists. In this case we can put it that political activists dominate in the media discourse; they are supplemented with specialists representing various fields, and, grounding on their statements, a politically engaged context is constructed. Moreover, it is important to note that comprehensive journalistic investigations are very rare; usually, as was mentioned, general information is rendered in relation to economic events or expression of opinions of politicians, whereas participation of experts in various fields, representatives of environmental and other organizations is vague.

The political engagement in nuclear issues in the media coverage discourse highly manifested itself when the constitutional type referendum on the construction of a new nuclear power plant was held in Lithuania. In 2012, the referendum blocked the construction of a new nuclear power plant, since more than $65 \%$ of Lithuanian citizens voted against it. Politicians treat this referendum as a failure because an agreement with Hitachi had already been decided at the top governmental level and preliminary agreements had been made. Politicians expressed their regret in public by saying that the results of the referendum were determined by the media coverage, when public discussions were too politically engaged and there was too little of subject-related, matter-of-fact, expert assessment. The media coverage became a space where politicians dominated, and experts of other fields were poorly represented, and, consequently, an opportunity for politicians to express promises not based on expert opinions appeared. The media discourse created such public opinion and influence impacting the referendum which was unexpected by many political interest groups taking part in the public debate.

Thus, in the political sphere, energy security is related to national interests of being independent in economic and political regard. Leonavičius and Genys (2017) in providing the data of research conducted in 2013 demonstrate that energy security in the public discourse is called "the national goal"; goals of energy security are linked to "liberating society from the energy trap," "energy-related independence." In Lithuania, the political discourse is formed through participation of the following actors: President, Prime Minister, Minister of Energy, representatives of the ruling coalition, political opponents.

In the case of Lithuania, participation of scientists and scholars (experts in the nuclear and other fields) in the public discourse was insufficient; however, their opinions and positions in the public discourse could be important in discussions on the issues of energy safety development and seeking to involve members of society in the forming of a sustainable development conception, as well as increasing the level of understanding in the case of the scientific discourse. As Balžekiene (2006) 
puts it, based on scientific arguments it is possible to send a clearer message to the society in terms of existence of power and risk as well as the essence of energyrelated decision-making at the political level.

To sum up, in this case the media discourse lacks a critical and generalizing analysis of the themes based on comprehensive investigation or information provided by representatives of science and various stakeholder organizations. Politicians lacked the will to talk about long-term and economically reasoned projects while assessing the arguments of risks and longevity. Moreover, public opinion was little regarded and there was a lack of mechanisms to recognize risks when solving the issues of the policy on energy security (Leonavičius \& Genys, 2017).

\section{METHODOLOGY}

Fairclough (2013) points out that critical discourse analysis encompasses three analytical processes which are interrelated and intertwined with three dimensions of the discourse. These discourse dimensions are:

- text (description: the formal characteristics of a text),

- discursive practice (interpretation: the relationship between the text and interaction),

- socio-cultural practice (explanation: "social determination of the processes of production and interpretation and their social effects") (see Figure 1).

\section{Data collection}

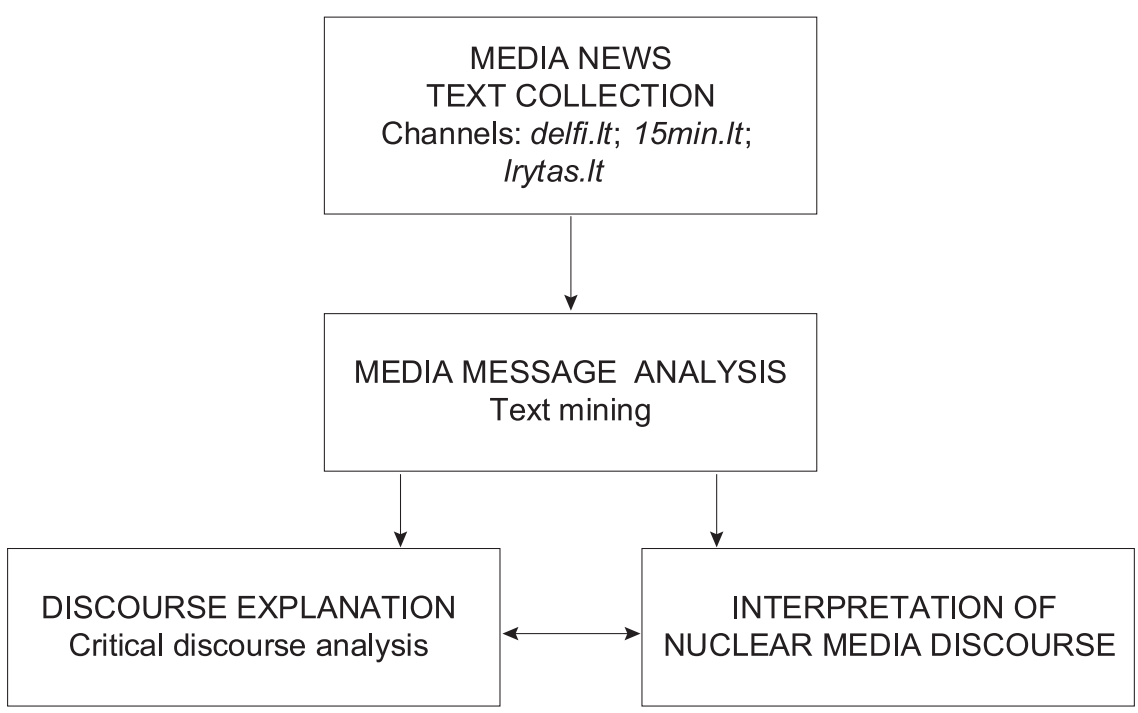

Figure 1. Media discourse dimensions

Source: adapted from Fairclough (2013). 
To collect the data, the following steps have been taken: i) choosing the three most popular media news portals; ii) exploring the online articles published over the last 15 months (June 2017-August 2018), including specific keywords; iii) choosing the articles for the data analysis.

We used big data mining (e.g., Fan \& Bifet, 2013; Wu et al., 2014) for the data collection from media news portals Delfi (Delfi.lt), 15min (15min.lt) and Lietuvos rytas (Lrytas.lt). Official statistics ranked these national social media news portals as the most visited. According to statistics, in December 2017 Delfi had more than 519,000 readers per day and more than 1.2 million readers per month; $15 \mathrm{~min}$ had more than 402,000 readers per day; and Lietuvos rytas had more than 305,000 readers per day (Media audience overview, n.d.).

Data mining employing the Python programming language (python.org) was used to screen the articles published over the period from June 2017 to August 2018 from these three Internet news portals, including the keywords "INPP" and "Visaginas." The articles which included the keywords "INPP" and "Visaginas" were chosen for their critical discourse analysis and social network analysis. Detailed information on the articles found is presented in Table 1.

Table 1. Number of articles selected for further analysis (based on keywords)

\begin{tabular}{|c|c|c|c|c|}
\hline No. & Media channel & "INPP" & "Visaginas" & In total \\
\hline 1. & Delfi.lt & 73 & 43 & 116 \\
\hline 2. & 15 min.lt & 56 & 46 & 102 \\
\hline 3. & Lrytas.lt & 76 & 36 & 112 \\
\hline & In total: & 175 & 125 & 330 \\
\hline
\end{tabular}

Source: Authors.

The following information retrieved from the selected articles was considered for extended analysis: i) the date when the article was uploaded online; ii) author(s) of the article; iii) heading of the article; iv) summary of the article; v) amount of comments to the article; vi) theme of the article.

\section{Data analysis}

In the data analysis media texts from the selected articles were researched, in seeking to find nuclear media discourses (Figure 2). 


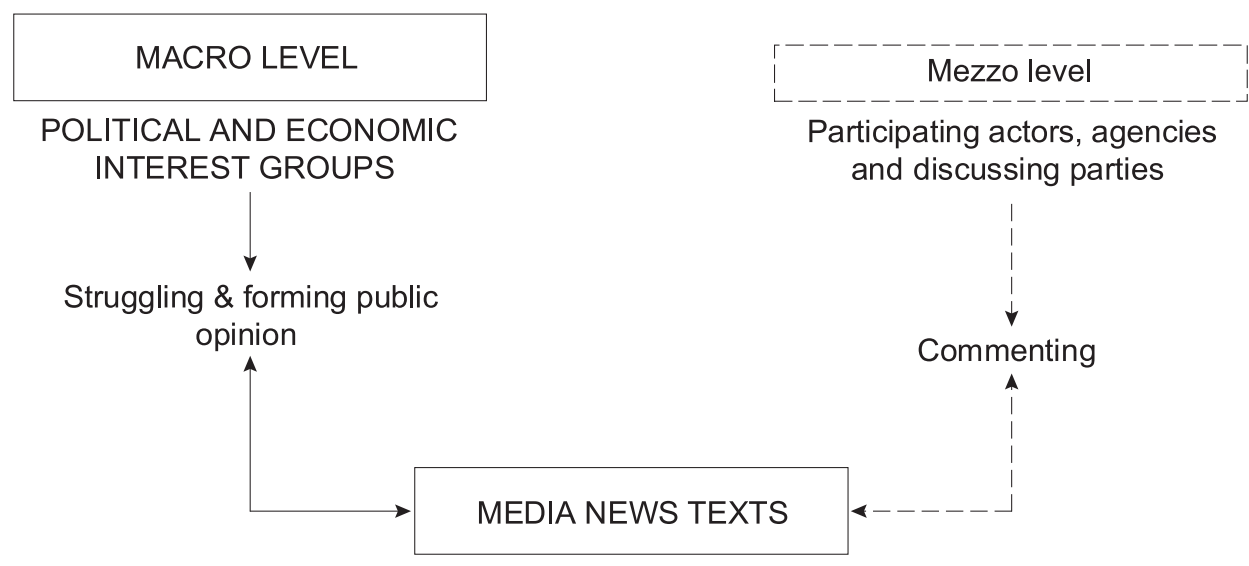

Figure 2. Themes and structures of analysis in the process of discourse creation

Source: adapted from Ball-Rokeach (1998, p. 15).

\section{Social network analysis of the data}

Additionally, we applied social network analysis (Scott, 2017) for the visualization of the main discourse themes. We used Python and collection of network analysis tools iGraph. The articles and discourse themes collected as primary data served as nodes and edges of the undirected secondary data graphs. We visualized discourse themes separately for each news media channel. The data analysis employed the methods of social network analysis. The algorithm has been created in the following way:

a) The key events described and presented in online portals over the period of investigation (15 months) have been pointed out. These described key events were given titles-themes. The events were related to some period when they were discussed the most (or discussed at all). When drawing the network, the following data has been singled out: i) the date when the event "appeared," i.e., an article was published; ii) the very event; iii) other events that took place at the same time or were related (through key words) to this event. The node of the network indicates the articles which were selected in compliance with the keyword "INPP." A diamond indicates the events related to the community after selecting the articles including the keyword "Visaginas."

b) The edge of the network (correlation between events) is the line linking the described events. The arrangement of the events is not linear in terms of time; therefore, the network nodes are situated in space in order to make it possible to see them. The correlations between the events demonstrate the following: i) the events are interrelated in terms of time; ii) the articles mentioning one event also mention (or there is a hint of) another one. For example, the events "waste storage" and "incident" are 
linked because articles on them were published at the same time (or almost simultaneously) and at least in one article another theme is discussed (when dealing with waste storage, the incident is mentioned).

\section{RESULTS}

The research data demonstrates that over the period of investigation in 2017-2018 the funding of the decommissioning of the INPP is one of the major themes (Table 2).

The media articles discuss how the authorities of the INPP, Ministries of Energy and Finance, and other actors negotiate the assurance of the EU funding until completing the decommissioning works. When a new period of funding of the decommissioning works approached, the media articles recalled that the previously foreseen financial means were insufficient, and the costs of decommissioning significantly increased. The details of negotiations with the INPP (works of demolishing the reactors, details of the project on management of radioactive substances) are discussed, the orientation toward the planning of works in the framework of a new stage is also revealed. The awaiting works of decommissioning of the reactors projected for 2023 are constantly mentioned and a request to have more active sharing of the financial load among EU member states is emphasized. When reviewing the implemented works and planned demolition, portals Delfi (14 articles), Lietuvos rytas (10 articles), $15 \mathrm{~min}$ (8 articles) continuously mention the millionth sums of money and underline that the works to close the INPP proceed "quite rapidly" and "effectively." When discussing the opportunities to increase funding through dialog with EU representatives, the statement of the Minister of Energy is cited: the obtained experience gained during the decommissioning of the INPP will be unique and "later Lithuania will become a good example for other countries" (portal Lietuvos rytas). The portal 15min, besides information on the negotiations concerning the funding, mentions that the closure of the INPP was a condition of entry to the EU and the EU is the institution funding this decommissioning. The state enterprise INPP itself (its authorities), representatives of ministries (usually representatives of the Ministry of Energy), the government, and politicians are major actors of this theme and likely sources of the discourse. It is important to note that in discussions on the issues of funding of the decommissioning of the INPP and financial support to the synchronization of electricity networks of the Baltic states in discussion with the officers of the European Commission, they deal with the safety of the Astravets Nuclear Power Plant in Belarus, too.

Another theme that appears in all portals is also related to funding; however, there is a discussion on accountability for the financial means used. The presented information is related to delegations of European Parliament members and their visits to the INPP to monitor the effectiveness of the use of EU financial support and the progress in the decommissioning process. These are the discussions on the arriving members of the European Parliament wishing to be acquainted with the project of the decommissioning of the INPP and the proceedings of the work being carried out. 
Natalija Mažeikienė, Judita Kasperiūnienė, Ilona Tandzegolskienė

Table 2. Themes in the nuclear media discourse (2017-2018)

\begin{tabular}{|c|c|c|}
\hline Themes & $\begin{array}{l}\text { Subthemes highlighted in the media } \\
\text { discourse }\end{array}$ & $\begin{array}{l}\text { Subthemes distinguished during the } \\
\text { phase of interpretation and applying } \\
\text { CDA }\end{array}$ \\
\hline \multicolumn{3}{|c|}{ The decommissioning of the INPP } \\
\hline \multirow{3}{*}{$\begin{array}{l}\text { Funding of the } \\
\text { decommissioning }\end{array}$} & $\begin{array}{l}\text { Negotiations on the assurance of } \\
\text { funds }\end{array}$ & \\
\hline & Financial support from the EU & \\
\hline & $\begin{array}{l}\text { Effectiveness and accountability } \\
\text { for the financial means used }\end{array}$ & \\
\hline $\begin{array}{l}\text { Management of the } \\
\text { decommissioning }\end{array}$ & $\begin{array}{l}\text { Financial and managerial } \\
\text { non-transparency and links to the } \\
\text { criminal discourse }\end{array}$ & $\begin{array}{l}\text { Lack of information on techno- } \\
\text { logical aspects of decommission- } \\
\text { ing }\end{array}$ \\
\hline \multirow{3}{*}{$\begin{array}{l}\text { Technological process } \\
\text { of the decommission- } \\
\text { ing }\end{array}$} & $\begin{array}{c}\text { Rapid and effective demolition } \\
\text { works }\end{array}$ & \multirow{3}{*}{$\begin{array}{l}\text { No information on complexity, } \\
\text { challenges and risks of the } \\
\text { technological process }\end{array}$} \\
\hline & $\begin{array}{l}\text { Simplified image of demolition } \\
\text { (mechanical disassembling of } \\
\text { aggregates to parts) }\end{array}$ & \\
\hline & $\begin{array}{l}\text { Technological discrepancies (“an } \\
\text { incident”) }\end{array}$ & \\
\hline \multirow{2}{*}{$\begin{array}{l}\text { Radioactive/nuclear } \\
\text { waste storage }\end{array}$} & \multirow{2}{*}{$\begin{array}{l}\text { Public procurement procedures } \\
\text { and sources of funding }\end{array}$} & $\begin{array}{l}\text { Lack of information on techno- } \\
\text { logical aspects of building the } \\
\text { waste storage facility }\end{array}$ \\
\hline & & $\begin{array}{l}\text { Lack of information on environ- } \\
\text { mental aspects and possible risks } \\
\text { in waste storage }\end{array}$ \\
\hline \multicolumn{3}{|c|}{ Visaginas as a satellite town of the INPP } \\
\hline \multirow{2}{*}{$\begin{array}{l}\text { Social and economic } \\
\text { problems of Visaginas }\end{array}$} & $\begin{array}{l}\text { Dying mono-industrial town of } \\
\text { the closed INPP }\end{array}$ & \multirow{4}{*}{$\begin{array}{l}\text { Lack of citizens voices; } \\
\text { lack of information on cultural } \\
\text { and social life of the town; } \\
\text { lack of representations by the } \\
\text { inhabitants and their accounts }\end{array}$} \\
\hline & Social problems & \\
\hline \multirow{2}{*}{$\begin{array}{l}\text { The second-chance } \\
\text { opportunities of the } \\
\text { town }\end{array}$} & $\begin{array}{l}\text { New initiatives contributing to } \\
\text { potential economic revival }\end{array}$ & \\
\hline & $\begin{array}{l}\text { Search of a new identity of the } \\
\text { town in ongoing art projects }\end{array}$ & \\
\hline
\end{tabular}

Source: Authors.

Along with the issues on the funding of the decommissioning, another important group of themes, issues of the management of the decommissioning, becomes more 
apparent. There is a special theme of the news for mass media coverage - the theme of non-transparent management and misuse. The misuse in organizing the sales of the property of the INPP at an auction and arranging public procurement, competitions to perform complex operations is disclosed. The themes of financial and managerial non-transparency are linked to the criminal discourse. Many of these news entries are presented under the rubric "criminal cases." A separate theme of the news on the INPP is related to the identified violations: it is a theme on the resignation and expulsion of authorities of the state enterprise, substituting them with others or new managers while organizing a review of performance of previous authorities. The Ministry of Energy, the Government, and the INPP itself are the sources of this discourse. Other interested groups, i.e., political and economic interest groups taking part in this process of the substitution of the authorities and appointment of new managers no doubt, stand behind this discourse.

Waste storage is one of the most pronounced themes. The competition to purchase and fund the services of arrangement of the works of radioactive waste storage also receives much attention, and the competition specification for technical supervision of the construction is the focus. When presenting this theme, investment of hundreds of millions into the works of construction of radioactive repositories and longevity of these repositories is indicated. This theme is broadly introduced in all 3 portals: Delfi ( 7 articles), 15 min (6 articles) and Lietuvos rytas (4 articles). However, there is a broader focus on the subtleties of public procurement, sources of funding; the numbers of the auxiliary zone of the storage and infrastructure constructions, as well as the covered area are introduced. In this case, there is little discussion on the technological and environmental aspects of waste storage. It is important to note that other means of communication (not just the press) emphasize this theme in dealing with technological and environmental aspects in waste storage. For instance, the technological and environmental aspects of the demolition are presented in detail in booklets, short films issued by the INPP Information Centre and in its exhibition premises; nevertheless, only a small part of society, i.e., visitors of the center and groups of specifically interested individuals (scientists, students, other tourists and visitors), may get acquainted with this discourse.

It was noticed that the technological side of its decommissioning is not sufficiently discussed in the press. There is no discussion on the aspect that the decommissioning of the power plant is a complex and complicated process which involves many technological challenges; there is specific uncertainty in foreseeing the search for solutions. The presented technological aspect is reduced to a simplified image stating that it is just demolition, mechanical disassembling of aggregates to parts, which would mean a simplification of the decommissioning. The absence of the discussion on the technological complexity and the challenges could be treated, on the one hand, to manage the perception of the decommissioning risk (to reduce the perceived risks) in public; on the other hand, this technological area is left for the expertise of technologists and experts of the INPP. Meanwhile, the 
technological discrepancies taking place in the context of not disclosing the technological aspects of the decommissioning related to the complexity of the technological process attract much of the attention of the press and become very important scandalous news. One of the important themes in mass media deals with the discussion of a discrepancy that happened at the INPP (in the press called "the incident,") when an altered level of radioactivity was registered while conducting testing and transporting substances polluted with radiation from old storage facilities to new ones. In provision of the information on this incident, the Ministry of Energy and the INPP were criticized for concealing this incident. The imbalanced discourse on the insecurity and risks is observed. On the one hand, the overall technological complexities of the demolition and potential threats (to environmental protection, health of residents) are not discussed in general; the object and works proceeding there are purposefully presented as secure and reliable (without risks). On the other hand, technical "incidents" during testing related to the overall technical complexity of the process and potential risks cause a stormy reaction in mass media coverage underlining other aspects - expressing dissatisfaction with reticence, secrecy, acting behind closed doors.

The majority of articles on assurance of the funding, non-transparency of management, occurred incidents, substitution of authorities is prepared in compliance with the press releases issued by the Communications Department of the INPP; in their turn, they are coordinated with both authorities of the INPP and appropriate institutions (ministries, particular services). These are thoroughly prepared and adjusted texts which are published in press almost without interpretations, discussions, participation of additional journalists (without comprehensive investigations, interviews with experts of nuclear energy, etc.). While analyzing the presented messages, it has been found out that usually the head of the Communications Department of the INPP provides information on various questions related to the INPP to the mass media, and the messages are short and usually presented after the comments of the representatives of the Ministry of Energy.

A separate secondary and less presented theme on the portal Delfi deals with the small town of Visaginas, which is a satellite town to the INPP, and its community. Social network analysis of articles and themes revealed that these themes are scattered, unrelated and not interconnected (Figure 1,2 and 3). The same tendency was observed in the other two media news portals. We found the lack of citizens' voice in discussions and debates in all the channels. There are incomparably fewer articles on Visaginas and its community than on matters concerning the INPP. Usually, articles on Visaginas are reports prepared by journalists who communicated with residents.

Two tendencies of depiction have been discovered. On the one hand, there are articles where the town is characterized as dying, having social problems, as a mono-industrial town whose major and town-forming enterprise, INPP, is undergoing closure. On the other hand, a new tendency appears and becomes apparent: 
to depict newly-born prospects of the town. The closed INPP is introduced as an attractive site capable of reviving the town for a new life, and this is entitled "The Second Opportunity of the Nuclear Monster." When projecting the future of the town, ideas of famous residents of Visaginas dedicated to the revival of the town are presented. The proceeding of investment and attraction of foreign capital is introduced. Again, the arrival of new investors in Visaginas promises recovery and new hope. The portals discuss the foreign investors who will build a factory and plan to employ 1,000 new staff. The new life here is understood as implementation of interesting and innovative activities and attraction of visitors through various projects. The portals under analysis deal with the search for the town's identity, present a discussion series on the topic of the town, consider a documentary theater performance A Green Lawn as an unfinished story of Visaginas, indicate Visaginas as an object of photographic investigation, introduce a film on Visaginas, $A$ Town of Butterflies. The cultural news presented in the portals invites us to watch a series of films on Visaginas' youth and untangle problems of this town jointly with young film directors, discussing the identity and culture of the town. The portals present the music festival, Visaginas Country, held for 20 years, and other music events related to the identity of the town. A project worked out by investigators of the social sciences to develop nuclear tourism is introduced. The life stories of individuals introduced in the portals sound like a hope to revive Visaginas. Nevertheless, all three portals lack the themes which were related to the changes in Visaginas, its cultural and social life. The uploaded articles are single and do not repeatedly occur, they become "inserts" in the general flow of information on the issues of the closure of the INPP. Analysis of the discourse of the previous decade reveals that then, when the works of the ceasing operation of the reactors proceeded, much attention was paid to the history of the INPP and Visaginas. After the INPP electrical energy supply ceased, interest in this object declined.

Referring to the peculiarities of construction and media discourse on nuclear power described by Gamson and Modigliani (1989), we recognize specific "media packages" as interpretative frames in media coverage of the INPP and its satellite town Visaginas. Prevalence of certain themes and and absence or lack of other topic coverage are recognized. When dealing with the decommissioning of the INPP, the themes of publicity, financial transparency, compliance with laws dominate; they reveal the financial, legal discourse of administration. The decommissioning is almost not communicated as a complex technological process of demolition involving challenges and the likely impact on the environment and community. This discourse is being constructed mostly by the INPP, the ministry and mass media itself. This discursive strategy is directed toward reducing the perceived risk of nuclear power.

Environmental and social aspects of the decommissioning are not sufficiently disclosed and discussed. Waste storage as a technological process, a theme of environmental security and potentially the social theme are also presented only through the 


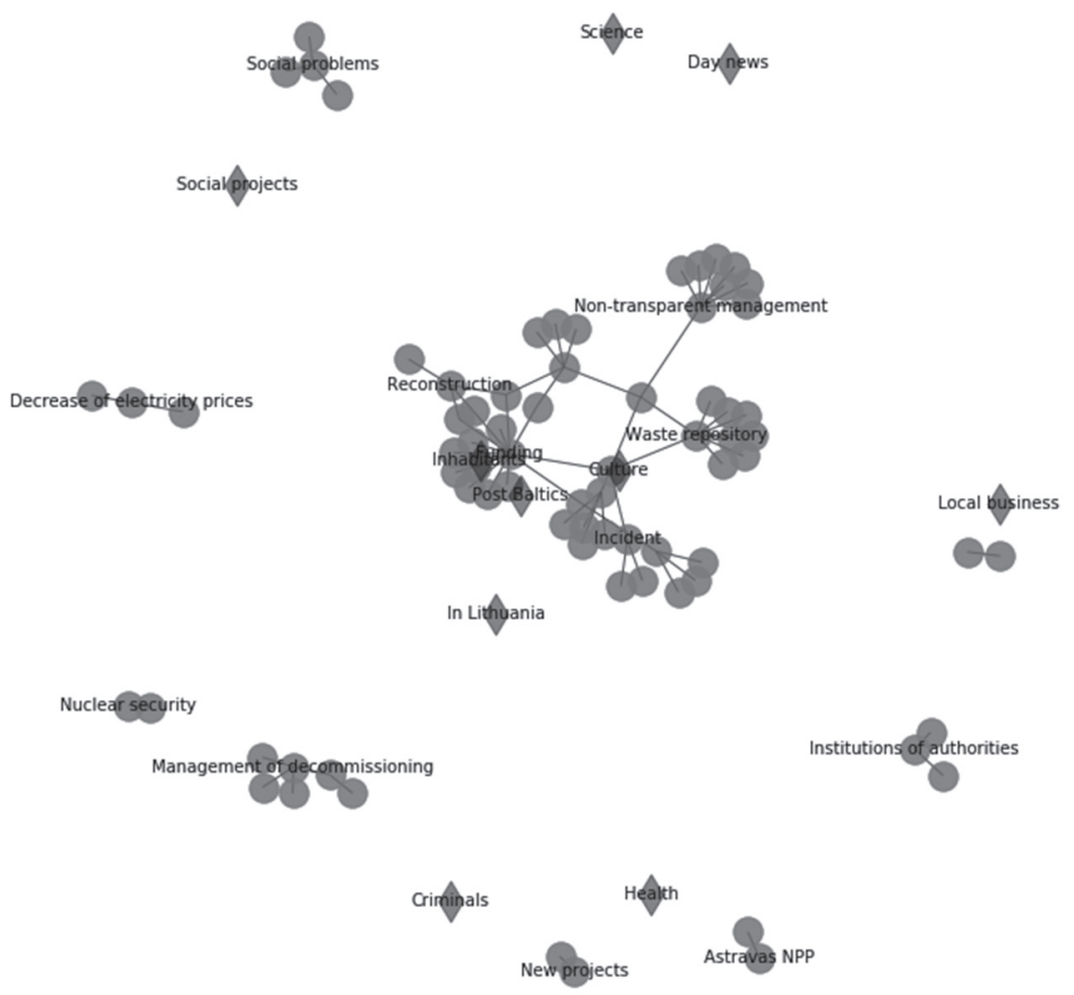

Figure 3. Social network analysis was applied to explore themes on nuclear issues in Delfi.lt during the period June 2017-August 2018. The main official discourse on the INPP is marked with circles; the discourse on Visaginas' community is marked with diamonds.

Source: Authors.

discourse of administration, finances and public procurement. There are no discussions on how the environmental aspects of waste storage are being solved, what challenges and problems of radioactive waste burial exist and how this will affect the lives of the local community and inhabitants of the entire country. The discursive strategy is to substitute one theme (environmental security) with other ones (finances, public procurement).

Appealing to the definition of media discourses given by Gamson and Modigliani (1989) a specific issue culture - the culture of nuclear power is revealed. In the described Lithuanian nuclear discourse in 2017-2018, the communicative patterns and larger cultural themes discussed by the authors analyzing the nuclear discourse (e.g., Gamson \& Modigliani, 1989, Kinsella, 2005; Anshelm, 2010; Catellani, 2012) are recognized. First of all, the four major themes linked to nuclear energy: mystery and entelechy, potency and secrecy, the construction of a "modernistic" basic narrative of nuclear power as inevitable technological development, are delineated. The 


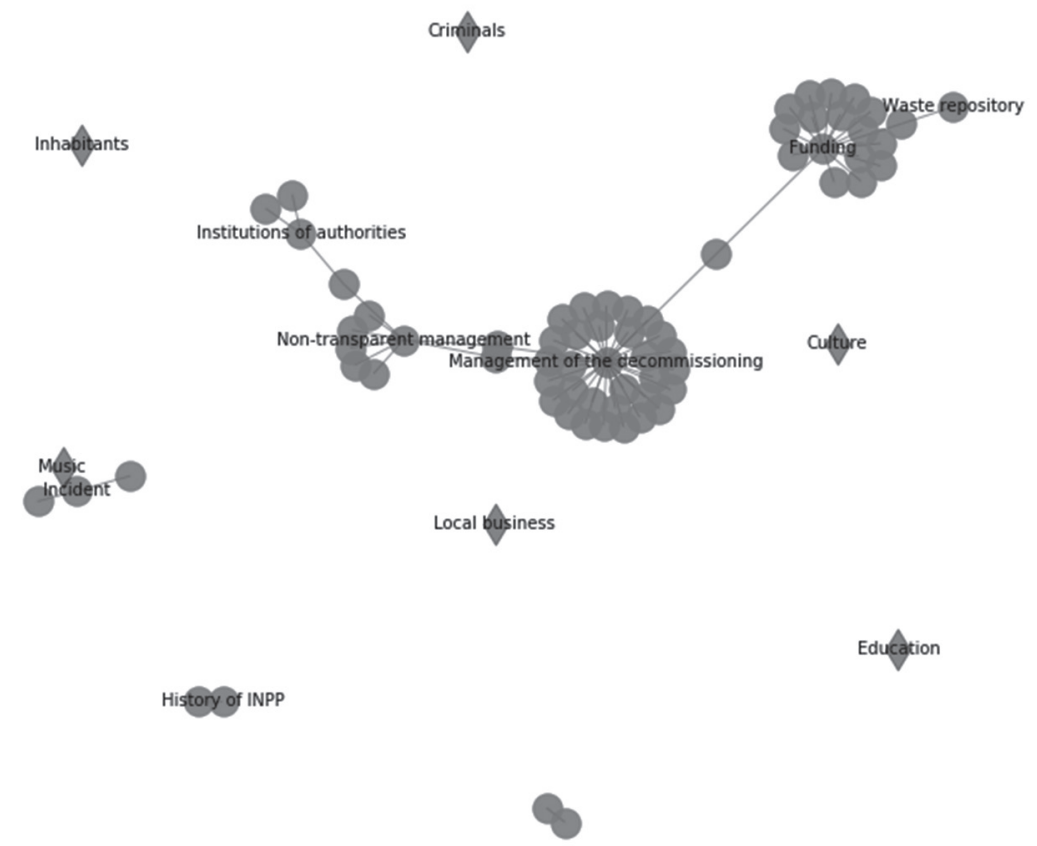

Figure 4. Social network analysis was applied to explore themes on nuclear issues in the portal $15 \mathrm{~min}$ during the period June 2017-August 2018. The main official discourse on the INPP is marked with circles; the discourse on Visaginas' community is marked with diamonds.

Source: Authors.

energy-related situation in Lithuania linked with the decommissioning of the only nuclear power plant supposes an idea that the potency of nuclear power, technical and economic capabilities are no longer relevant; what once was a powerful nuclear power plant in terms of the size and capacity of nuclear power plant construction, the amount of produced electricity - all this is no longer important and has no sense in being discussed. It should be noted that Kinsella (2005), Anshelm (2010), Catellani (2012) revealed the theme of the potency of nuclear energy when talking about the beginning of nuclear energy, its increase and civilization-linked promises. The INPP is in its decline stage, when "the nuclear genie," since it was not properly restricted and controlled at a proper time (closure of the INPP because it is of the same model as at Chernobyl, which is technically treated as insecure), is being thrust back into the bottle because its services are no longer required and its mission did not prove to be useful. However, this cultural narration and the myth of the potency of nuclear power manifests itself in the Lithuanian media discourse in 


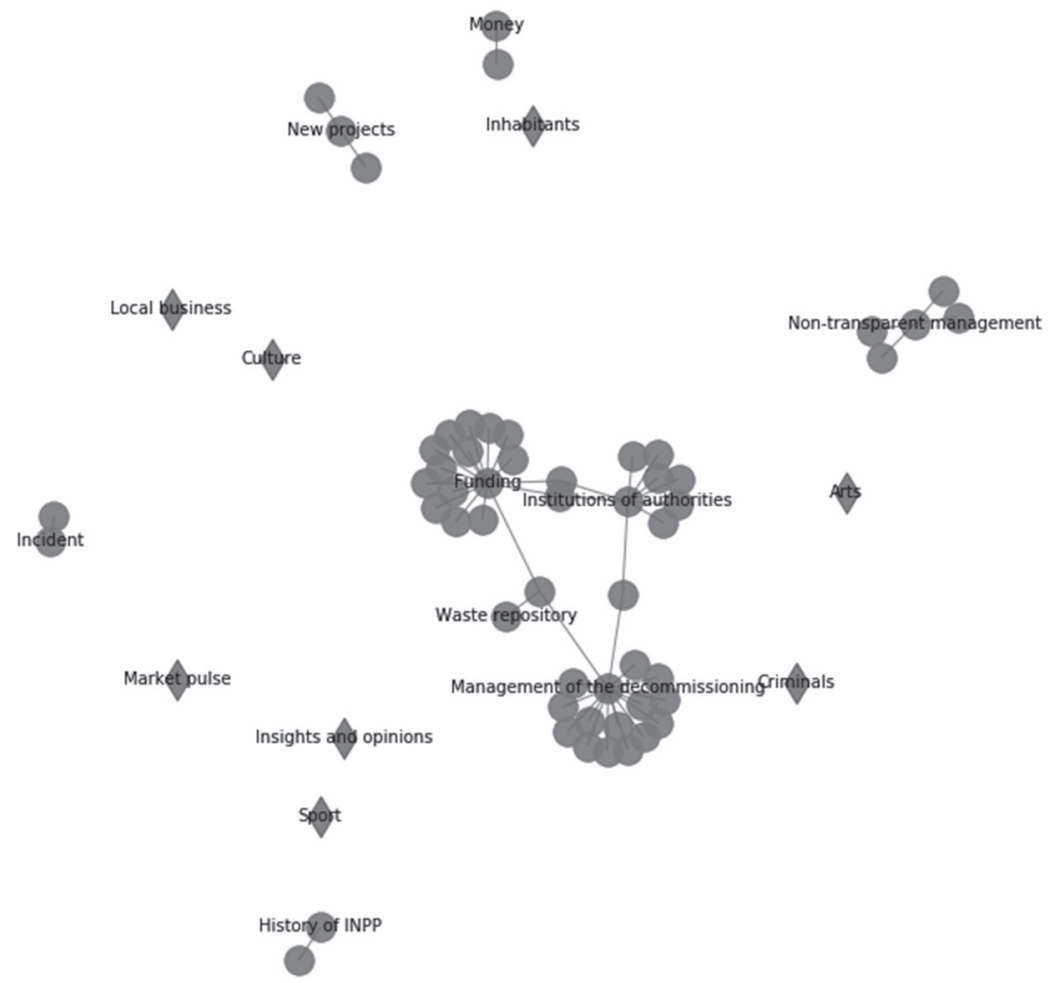

Figure 5. Social network analysis was applied to explore themes on nuclear issues in Lrytas.lt portals during the period June 2017-August 2018. The main official discourse on the INPP is marked with circles; the discourse on Visaginas' community is marked with diamonds.

Source: Authors.

a modified way as an idea that the demolition of the nuclear power plant is a very responsible task that will be carried out competently and safely by top-level nuclear specialists.

The "modernistic" basic narrative of nuclear power described by the mentioned authors, where the use of nuclear energy is associated with technological progress, increased productivity and competitiveness, in the case of the Lithuanian discourse does not manifest apparently through ideas stating that nuclear energy is related to economic growth and new jobs, since the nuclear industry itself is in a state of closure. Nevertheless, the belief in science and the idea of the Enlightenment holding that there is the power of science to control nature manifests through the belief in that technological and environmental aspects of decommissioning of the INPP will be reliably solved by experts of the INPP. An absence of attention focusing on technical subtleties of the decommissioning of the INPP and waste storage in the discourse is a recognition that this area is left for the competence and responsibility of technologists and 
scientists of enterprises. Here, the belief in the power of science is implemented in the hope that the decommissioning itself (technological, environmental aspects) proceeds while trusting experts, the scientific and technical expertise of specialists, other staff members working in the INPP, and this is not a subject of public debate or doubt, society must not be aware of or know about it. The theme of the mystery and secrecy can be indirectly found. An absence of technological and environmental expertise and scientific discussion in the press also implicitly suggests that if such discussions proceed not in public, they take place in other spaces of work and discussions of nuclear specialists which are hidden from society (as Anshelm [2010] writes, where magicians and wizards accomplish their miracles). The analysis of the Lithuanian discourse basically demonstrates the tendency recognized by foreign authors: technological, scientific aspects of nuclear power are a subject out of the control and intervention of ordinary citizens.

Looking at the empirical data through the theoretical lens of media framing (Gamson \& Modigliani, 1989), besides the interpretative frame and revealed features of the culture of the nuclear issue, the role of sponsors of the media discourse and media practices in Lithuania can be pointed out. Findings of the research echo the statements of other authors investigating the nuclear discourse in relation to the participants and stakeholders (e.g., Kinsella, 2005; Catellani, 2012; Entman \& Rojecki, 1993; Balkan-Sahin, 2019; Mercado-Saez et al., 2019). The interrelation between power, knowledge, and construction of docile citizenship, when discursive control and regulation by determining groups and agents who can speak about nuclear matters is implemented, is emphasized by these authors and becomes apparent. Like in other countries, in the Lithuanian nuclear discourse, the participants holding political and economic power (INPP, governmental institutions, ministries and other controlling authorities, the EU as the institution funding the INPP project) prevail. The majority of the articles have been written based on press releases prepared by the Communications Department of the INPP or the Ministry of Energy and through collaboration with them. The Minister or Vice-minister of Energy, representatives of the Communications Department of the INPP and single politicians are the speakers who usually appear in the discourse, present their comments. The content of these informative articles is thoroughly prepared and coordinated; it can be said that this is one-way, controlled communication, which is presented by one source, without significant corrections, supplements made by a news portal, or discussions. Usually, the portals present in the form which was given by the primary sources and participants (INPP and other state institutions). Also, there is lack of consistent or comprehensive journalistic reporting which would let us find interesting or new thematic fields oriented towards the revelation of the theme and historical (narrative) depiction.

It should be stressed that media discourse analysis presented in this article reveals coverage of the nuclear issue by the most popular commercial online portals (Delfi, 15min, Lrytas) which have a profound influence on public opinion. The 
national broadcaster LRT (The Lithuanian National Radio and Television) news portal lrt.lt could be a very important non-commercial source of information on the nuclear issue. However, this portal does not belong to the most popular news portals, its potential influence on the audience is rather small (in 2017 it was included into the list of 10 of the most popular news portals).

Commercial online newspapers create their content on the basis of several resources - the content (for instance, press releases and articles) received from news agencies (BNS - Baltic News Service, ELTA), other resources and the content produced by journalists. The main source of profit is advertising that is placed on the website next to the content. One more profit generation source is contracts with organizations and companies which pay for publishing their content. There should be a special indication in the content showing that it is ordered and paid. In the media coverage of the INPP and the town of Visaginas it could be seen from the data that the content was taken either from news agencies or prepared and written by journalists (Table 3).

Table 3. Number of articles selected for further analysis (based on keywords)

\begin{tabular}{|c|c|c|c|c|c|c|}
\hline $\begin{array}{c}\text { Sources of } \\
\text { the content }\end{array}$ & $\begin{array}{c}\text { Delfi on } \\
\text { Visaginas }\end{array}$ & $\begin{array}{c}\text { Delfi on } \\
\text { INPP }\end{array}$ & $\begin{array}{c}15 \text { min on } \\
\text { Visaginas }\end{array}$ & $\begin{array}{c}15 \mathrm{~min} \text { on } \\
\text { INPP }\end{array}$ & $\begin{array}{c}\text { Lrytas on } \\
\text { Visaginas }\end{array}$ & $\begin{array}{c}\text { Lrytas on } \\
\text { INPP }\end{array}$ \\
\hline $\begin{array}{c}\text { News } \\
\text { agency } \\
\text { BNS }\end{array}$ & 9 & 43 & 8 & 24 & 5 & 33 \\
\cline { 2 - 7 } & $20.93 \%$ & $\mathbf{5 8 . 9 0 \%}$ & $21.05 \%$ & $31.58 \%$ & $10.87 \%$ & $\mathbf{5 8 . 9 3 \%}$ \\
\hline $\begin{array}{c}\text { News } \\
\text { agency } \\
\text { ELTA }\end{array}$ & 0 & $12.33 \%$ & 0 & 0 & 0 & 2 \\
\hline \multirow{2}{*}{\begin{tabular}{c} 
LRT portal \\
\cline { 2 - 7 }
\end{tabular}} & 0 & 1 & 3 & 5 & 0 & $3.57 \%$ \\
\hline \multirow{2}{*}{\begin{tabular}{c} 
Journalists \\
\cline { 2 - 7 }
\end{tabular}} & $79.07 \%$ & $27.40 \%$ & $71.05 \%$ & $\mathbf{6 1 . 8 4 \%}$ & $89.13 \%$ & $28.57 \%$ \\
\hline \multirow{2}{*}{$\begin{array}{c}\text { No. of } \\
\text { articles }\end{array}$} & $\mathbf{4 3}$ & $\mathbf{7 3}$ & $\mathbf{3 8}$ & $\mathbf{7 6}$ & $\mathbf{4 6}$ & $\mathbf{5 6}$ \\
\cline { 2 - 7 } & $100 \%$ & $100 \%$ & $100 \%$ & $100 \%$ & $100 \%$ & $100 \%$ \\
\hline
\end{tabular}

Source: Authors.

There were no articles with an indication that the content was ordered and paid. An assumption could be made that the commercial news portals publish the content on the INPP and Visaginas, seeking to maintain their reputation as a credible publicity provider which covers important events at the INPP as a strategic state company and in its satellite town. Another motive for publishing news is to generate content which would have commercial potential (improved readability and increased profit from advertising). A significant part of media coverage on the INPP 
is presented as scandalous issues (non-transparent management and corruption, technological incidents at the INPP, representations of the "dying and shrinking town of Visaginas") that gains the readers' attention.

\section{CONCLUSIONS}

The discourse on the INPP and Visaginas presented in all three portals has some commonalities and tendencies. The discussed themes are similar in the portals and the amount of publications on these themes is similar, too.

Over the period under analysis, the discourse of the INPP and Visaginas is dissociated from energy security and common discussion on energy in Lithuania. This theme continues undergoing considerations in the framework of the general discussion on energy, its future, which, on the one hand, is understood, since the INPP is no longer part of the energy system; on the other hand, elimination of the nuclear discourse from the overall energy discourse does not allow contributing to the development of higher energy-related literacy of the inhabitants, to a better understanding of energy-related decisions made in other countries. The discussions on the use of nuclear energy, everything related to future opportunities for the energy sector proceed in Europe and the world.

In the overall discourse of this theme, very little attention is paid to Visaginas (as a mono-industrial satellite town of the INPP) and town community. Part of a very important discourse about the town being introduced by artists in their pieces of art (documentary theater performance, documentary films, photography exhibitions) is presented in news portals without more extensively discussing the content of the artworks. Meanwhile, the discourse of artists in the very artworks, the town of Visaginas and its community are presented in a specific way: by showing the history of the town, the destinies of its people, a complex identity, by emotionally rendering the moods of the community after the closure of the nuclear power plant, by disclosing their hopelessness, searching for a new identity, construction of hope while raising relevant questions of the global nuclear discourse (e.g., waste storage).

Description of financial non-transparency and substitution of authorities reflect the outcome of participation of such participants as other important governmental institutions (which investigate financial mismanagement) and political and financial interest groups. The influence of economic and political agents occurs indirectly through presented and discussed events (substitution of authorities of the INPP, funding issues), takes place in a certain field of competition and the disputes of political actors (parties, lobbyists, interest groups).

When talking about the participants of the discourse in the period under analysis (in 2017-2018), we can observe the changed role of the discourse participants (activists of political parties); they are no longer active and visible participants of the discourse. During the previous decade (until 2013), the INPP was more strongly discussed in a broader context of energy security, where energy security was treated 
more in a geopolitical sense and in the aspect of economic purposefulness. Back then, representatives of various competing political parties and journalists interviewing politicians were major participants.

Invisibility of certain stakeholders and their poor participation are observed. In current public discourse on the decommissioning, there are almost no local experts-scientists of the energy and nuclear energy, other representatives outside the communication field of the enterprise (INPP) (staff members having technical and engineering expertise), also stakeholders-experts who are able to raise and discuss environmental issues (e.g., research institutes, universities, national, international agencies), various organizations dealing with environmental security, activists who are able to discuss social issues or they are invisible. This situation differs from the discourse in the previous decade when, even though participation of experts was insufficient in comparison with the domination of politicians, it was more recognizable and noticed than in the current period (in 2017-2018).

Moreover, the currently existing participation of business representatives and residents in the discourse is low. The role of journalists and artists is more active in expressing the voice of the local community. The majority of articles on the community of the town have been prepared by journalists writing articles involving the community of Visaginas and other public activists as well as by various art and culture critics who present comments on the proceeding of international, national, and local projects (exhibitions, theater performances, demonstration and discussion of documentaries). Nevertheless, the discourse of art is insufficiently presented in media coverage, and the potential of artists as participants of the nuclear discourse is not revealed. Conversely, in their work, artists raise important questions regarding the history of the town, the complex identity of its residents and its change, the feelings of the residents after the closure of the nuclear power plant. Artists raise and discuss the issues on the destiny of nuclear energy and environmental security.

The earlier discussed poor participation of the community, artists, experts of various fields (experts analyzing nuclear, environmental and social issues), representatives of NGOs in the discourse reveal the tendency observed in other countries - the disempowerment of the public in the nuclear discourse (e.g., Kinsella, 2005; Catellani, 2012; Entman \& Rojecki, 1993).

In the analyzed Lithuanian discourse, dualism of the depiction of the INPP and Visaginas was revealed. These two objects are usually described separately. On the one hand, such dualism can be explained by assuming that after the closure of the INPP as a major feeding enterprise the mono-industrial satellite town must search for the re-definition of the town's identity and construct its identity without nuclear energy and without the INPP. On the other hand, such dualism reflects a common trend characteristic of the entire nuclear discourse, creating a boundary between the industry and the public, between the experts and ordinary citizens. Implementation of a communications and PR campaign in relation to the construction project of the Onkalo storage facility in Finland is a case which demonstrates 
how this recognized dualism and boundary between industry and the community, between experts and ordinary citizens are attempting to cope with the representational level by applying specific storytelling strategies (Yli-Kauhaluoma \& Hanninen, 2014; Hanninen \& Yli-Kauhaluoma, 2014). In the case of the INPP and Visaginas, the question remains open; it could be discussed and solved by journalists, the public and communities, various stakeholders dealing with how it would be possible to create a common communicational sphere where debates proceed and creation of a common history appear, by more strongly relating the theme of the INPP to the visions of Visaginas' commu-nity and town, the re-defined identity and while empowering various participants of the discourse.

\section{ACKNOWLEDGMENTS}

This article presents findings of the research project "The Didactical Technology for the Development of Nuclear Educational Tourism in the Ignalina Nuclear Power Plant (INPP) Region (EDUATOM)." This research is funded by the European Regional Development Fund according to the supported activity "Research Projects Implemented by World-Class Researcher Groups" under Measure No. 01.2.2-LMTK-718 grant (No. 01.2.2-LMT-K-718-01-0084/232).

\section{REFERENCES}

Anshelm, J. (2010). Among demons and wizards: The nuclear energy discourse in Sweden and the reenchantment of the world. Bulletin of Science, Technology \& Society, 30(1), 43-53.

Augutis, J., Krikštolaitis, R., Martišauskas, L., Uspuras, E., \& Zutautaite, I. (2016). Energetinio saugumo tyrimų raida Lietuvoje [Development o energy security reasearch in Lithuenia]. Energetikas, 62(4), 232-246.

Balkan-Sahin, S. (2019). Nuclear energy as a hegemonic discourse in Turkey. Journal of Balkan and Near Eastern Studies, 27(4), 443-461. https://doi.org/10.1080.19448953.2018.1506282.

Ball-Rokeach, S. J. (1998). A theory of media power and a theory of media use: Different stories, questions, and ways of thinking. Mass Communication and Society, 1(1-2), 5-40.

Baločkaitè, R., \& Rinkevičius, L. (2009). Branduolinès energetikos diskursai Lietuvos žiniasklaidoje ir viešojoje nuomonèje: nuostatų takoskyros ir "kalbančiųjų klasės” formavimasis rizikos visuomenejje [Nuclear power discourse in Lithuanian mass media and public opinion: Attitudinal divergencies and the emerging talking and acting classes in the risk society]. Filosofija. Sociologija, 20(4), 259-270.

Balžekienè, A. (2006). Socialinis branduolinès rizikos suvokimas: teorinès įžvalgos ir jų refleksija Lietuvos visuomenès požiūriuose ị Ignalinos AE [Social perception of nuclear risk: Theoretical insights and their reflection in the attitudes of Lithuanian society towards the Ignalina NPP]. Doctoral dissertation at Kauno technologijos universitetas.

Catellani, A. (2012). Pro-nuclear European discourses: Socio-semiotic observations. Public Relations Inquiry, 1(3), 285-311.

Entman, R. M., \& Rojecki, A. (1993). Freezing out the public: Elite and media framing of the U.S. antinuclear movement. Political Communication, 10, 155-173. 
Natalija Mažeikienė, Judita Kasperiūnienė, Ilona Tandzegolskienė

Evans, A., \& Steven, D. (2007). Climate change: The state of the debate. New York, US: Center on International Cooperation.

Fairclough, N. (2013). Critical discourse analysis: The critical study of language. London and New York: Routledge.

Fan, W., \& Bifet, A. (2013). Mining big data: Current status and forecast to the future. ACM SIGKDD Explorations Newsletter, 14(2), 1-5.

Fuchs, C. (2017). Social media: A critical introduction. Los Angeles: Sage.

Gamson, W. A., \& Modigliani, A. (1989). Media discourse and public opinion on nuclear power: A constructionist approach. American Journal of Sociology, 95(1), 1-37.

Hanninen, H., \& Yli-Kauhaluoma, S. (2014). The social construction of nuclear community: Building trust in the world's first repository for spent nuclear fuel. Bulletin of Science, Technology \& Society, 34(5-6), 133-144.

Kinsella, W. J. (2005). One hundred years of nuclear discourse: Four master themes and their implications for environmental communication. In S. L. Senecah (Ed.), The environmental communication yearbook (vol. 2, pp. 49-72). Mahwah: Lawrence Erlbaum Associates.

Leonavičius, V., \& Genys, D. (2017). Energetinio saugumo sociologija. Monografija [Sociology of energy security: A monograph]. Kaunas: Vytauto Didžiojo universitetas, 144-214.

Mercado-Saez, M.-T., Marco-Crespo, E., \& Alvarez-Villa, A. (2019). Exploring news frames, sources and editorial lines on newspaper coverage of nuclear energy in Spain. Environmental Communication, 13(4), 546-559. https://doi.org/10.1080/17524032.2018.1435558.

Scott, J. (2017). Social network analysis. Los Angeles: Sage.

Wu, X., Zhu, X., Wu, G. Q., \& Ding, W. (2014). Data mining with big data. IEEE Transactions on Knowledge and Data Engineering, 26(1), 97-107.

Yli-Kauhaluoma, S., \& Hanninen, H. (2014). Tale taming radioactive fears: Linking nuclear waste disposal to the "continuum of the good." Public Understanding of Science, 23(3), 316-330. 